\title{
Orden social e imaginarios sociales (Una propuesta de investigación)
}

\author{
Juan-Luis Pintos de Cea-Naharro
}

Universidad de Santiago de Compostela. Facultad de Ciencias Políticas y Sociales

Departamento de Socioloxía e Ciencia Política. 15701 Santiago de Compostela. Spain

\section{Resumen}

A partir de los problemas actuales para definir las situaciones globales que condicionan los sistemas sociales, se detecta una tendencia generalizada de sustitución de los mecanismos de argumentación racional por los de seducción propios del discurso mediático. La elaboración de los nuevos discursos hegemónicos y de resistencia a la dominación exige una doble reconstrucción de la reoría y del mérodo. En el artículo se hace una propuesta compleja de investigación que parre de la vinculación entre las formas del orden social y los mecanismos de construcción (y desconstrucción) de los imaginarios sociales. Estos tendrían como función primaria la elaboración y distribución generalizada de instrumentos de percepción de la realidad social construida como realmente existente. Se incluyen en el texto algunos materiales de definición conceptual de los imaginarios, cuestiones de método y fuentes bibliográficas.

Palabras clave: orden social, ideologia, hegemonía, imaginario, metodologia, realidad social.

\section{Abstract. Social order and social imaginaries}

This piece of research tries to deffne global situations which condition social systems. New hegemonic discourses, through mass media, and new resitance forms to domination ate needed in order to construct and deconstruct social imaginaries. (Redaction)

Key words: social order, ideology, hegemony, imaginary, methodology, social reality.

Pertenece a nuestra experiencia cotidiana el asimilar lo más rápida e impunemente posible los cambios que se producen en nuestro entorno social. Sin embargo, en los últimos tres años han saltado todos los mecanismos que realizaban automáticamente este proceso.

En primer lugar, porque «nuestro entorno" no sólo ha superado ya la dimensión individual, familiar o local a la que estábamos habituados, sino que inclusive los límites nacionales de los Estados y los internacionales establecidos o 
en proyecto (NATO, CEE, Europa, UEO, etc.) se han vuelto excesivamente estrechos por efecto de los medios masivos de comunicación que nos proporcionan informaciones a nivel planetario.

Después, fallaron los "metadiscursos", los grandes paradigmas de interpretación del mundo y la sociedad, las teorías sociológicas y hasta las metodologías científicas largamente utilizadas. Las "Escuelas" particulares o bien se vuelven escépticas o caen en el dogmatismo fundamentalista. El resultado inmediato de estos fallos ha sido la creciente desconfianza con respecto a las propuestas explicativas de lo que sucede.

Finalmente, el vaciamiento sistemático al que están sometidos los discursos de las ciencias sociales en su relación a los ciudadanos - vaciamiento producido por la tecnología comunicacional homogeneizadora y trivializadora de los sucesos, o por la dimisión de los intelectuales de su papel histórico de mediadores del conocimiento de la realidad-, ha contribuido a que los sucesos que están aconteciendo tengan una única lectura, la propia del discurso dominante.

Desde una perspectiva contraria, aquella que busca la emancipación a través de la crítica del presente y la memoria del pasado, se plantea, pues, la exigencia de realizar una serie de tareas que trataré de enunciar y definir en este escrito.

Reconstruir el concepto de "situación" es una de las primeras, pues la principal arma de los dominantes siempre ha sido la separación cuantificadora de los elementos de los problemas sociológicos, suprimiendo cualquier marco (teórico o práctico) que articulara los datos entre sí y con un proyecto. Paralelamente, el discurso de las tecnologías informativas ha suprimido el momento del análisis sustituyéndolo por la más evidente ideología en modo mismo de referirse a los datos (p.ej. la utilización de porcentajes encubriendo los universos, la frabilidad, etc.), revistiéndola de un ropaje retórico (piénsese en la utilización del término "históricon como adjetivo para cualquier suceso o anécdota política o culrural) para producir un "efecto de realidad" transponiendo al acontecimiento los criterios de verosimilitud de lo imaginario.

La situación, pues, en la que vivimos podemos metaforizarla en riveles que representan ámbitos diferenciados de la realidad social que tiende cada vez más rápidamente a presentarse como planetaria. El nivel más básico y generalizable es el económico, entendiendo por tal la base productiva de obtención de recursos necesarios para la vida y bienestar de una población determinada, y los consiguientes procesos de distribución y consumo. Del marxismo vulgarizado se ha tomado por el discurso dominante un primario economicismo que trata de convertir los procesos económicos no sólo en mecanismos automáticos, sino también en utopías cuasi-sacralizadas, por ejemplo a través de la absolutización del "mercado". 
Un segundo nivel, claramerite diferenciado del anterior aunque articulado con él, es el politico, que en principio tiene que ver con las decisiones que toman los gobernantes acerca de la organización global de una sociedad y de las actividades que ejercen los ciudadanos de la misma cuando persiguen el interés público. En términos más exactos, el nivel político es el campo del ejercicio del poder. Lo que resulta cada vez más problemático son los ámbitos concretos de ese ejercicio y la definición de los sujetos que lo ejercen.

Junto a estos dos niveles prácticamente reconocidos en todos los discursos teóricos acerca de la sociedad se sitúa un tercer nivel todavía más problemático que los anteriores. Me refiero al ámbito denominado de la "cultura». No voy a entrar ahora en una presentación de los diversos tratamientos que se han dado a este nivel, ni tampoco al tipo de articulación con los dos anteriores, cuestiones que exceden los límites de este escrito. Me limitaré a definir este nivel como el nivel del conocimiento y de los imaginarios sociales. Tendríamos así que los dos campos principales en los que se concreta este nivel de una situación concreta son el campo de la ciencia (y la tecnología de ella derivada) y el campo de los imaginarios que organizan y regulan nuestra vida cotidiana.

La búsqueda de una nueva hegemonía obliga a la reformulación del discurso de los dominantes, para conseguir, en las circunstancias cambiantes, mantener firme la dominación. Frente a ello, se produce la necesidad de renovar, correlativamente, el fragmentario discurso de los dominados para seguir luchando contra el hecho de la dominación.

La primera batalla se disputa siempre sobre cómo definir la situación presente. $Y$ aquí comienza ya a manifestarse lo que denunciábamos en el párrafo anterior: la posición dominante trata de imponer una única y simplificadora lectura de los hechos. "Fracaso del comunismo en todos los frentes y victoria sin precedentes del mercado libre y la democracian, tales son en síntesis los titulares una y otra vez repetidos por los medios masivos. De esa defnición de la situación se deducen lógicamente toda una serie de consecuencias: "generosidad" con los "pobres" vencidos que bastante tienen con haber sobrevivido a los terrores del infierno; hay que "enseñarles" a gobernarse "democráticamente" y a entrar en los paraísos del mercado libre que ellos están anhelando; se abren nuevos territorios al negocio capitalista de la "modernización", mientras que algunos empecinados (Cuba, China, Vietnam) prefieren seguir anclados en el pasado y haciendo pasar hambre a sus poblaciones, atenazando sus voces de protesta con una férrea dictadura. De paso, en los países del uoccidente libre», se caricaturiza como totalitaria y atrasada cualquier propuesta de resistencia al sistema capitalista y a sus efectos perniciosos sobre los márgenes del sistema; el capitalismo ya no se discute, pues es lo único que se mantiene de la anterior situación, y lo que ahora importa es establecer un unuevo discurso del orden» que legitime las nuevas formas de barbarie info-tecnológica. 
Estas serían las líneas principales en la construcción del nuevo discurso dominante, que prácticamente "cabalga en solitario", pues los discursos críticos no se han repuesto todavía de la sorpresa ante lo sucedido. Habría que analizar detenidamente cómo se fueron perdiendo las batallas parciales, y cómo se produjo el desarme conceptual más drástico en la historia del pensamiento por parte de las fuerzas de izquierda. Pero ello supera nuestras intenciones y prioridades actuales.

Hay que reconocer que en el último decenio se ha producido un viraje socialdemócrata en el discurso de algunos marxistas. Paradójicamente, este viráje era paralelo al desmantefamiento del principal instrumento político de la socialdemocracia, el estado del bienestar. En nuestro país, en concreto, que caminaba hacia ese tipo de orden económico y político, nos hemos encontrado con que la izquierda se ha mantenido en el poder con una política económica y cultural claramente derechista. En otros países europeos (casos de Alemania y Suecia) la socialdemocracia ha tenido que alejarse de las instancias de poder por el imperativo de unos ciudadanos cautivos del espejismo reaganiano del "Minimal Stare». En el caso de España, la reordenación de los agentes economicos y políticos se ha encubierto bajo las anécdotas de los supuestos (y después reales) "enfrentamientos personales" entre líderes políticos y sindicales.

Como este proceso de renovación de la hegemonía está aún en curso, no podemos establecer con claridad las principales articulaciones del discurso dominante. En parte porque nuestro instrumental analítico es altamente deutdor de las circunstancias del pasado y en parte también porque se ha descentrado la ubicación intelectual del discurso emancipador y crítico. Pero ello no puede impedir que apuntemos aquí unas líneas de fuerza que ya se adivinan.

1. Posición fuerte del determinismo de los procesos históricos y sociales, con la correspondiente supresión de los sujetos individuales y colectivos y de sus responsabilidades.

2. Restablecimiento de un "darwinismo social" (absoluta desprotección de los "débiles" de todo tipo), con una clara tendencia a presentar los procesos sociales como sometidos a "leyes naturales".

3. Ruptura y desagregación de las ámbitos "públicon y "privado" por el creciente sometimiento al mercado (omnipresente a través del discurso publicitario) de las relaciones personales y de la toma de decisiones políticas (procesos de monetarización y burocratización, según J. Habermas).

4. Tendencia global a la renovación de los Imaginarios Sociales. Sustitución de los mecanismos de argumentación por los de seducción. Supresión de cualquier referencia a "fines"; discurso cerrado en los medios y la tecnología.

\section{III}

Frente a esta situación se está empezando a recuperar algo de lo que fue el papel crítico de los intelectuales en los tiempos ya pasados. Todavía con tanteos 
y experimentos, con dudas y desconfianza, pero con intención clara de redefinición conceptual, van apareciendo obras en las que - más allá de la perplejidad y el desencanto- se van plasmando corrientes de pensamiento que tratan de definir la situación actual y las rareas intelectuales de nuestro tiempo de un modo diferente, $y$ en algunos casos contrapuesto, al del discurso dominante en formación.

A modo de ejemplo, tendremos que referirnos a obras como la de Gilles Deleuze \& Felix Guattari, Qu'est-ce que la philosophie? (París, 1991), en la que, frente a la pretendida reducción de la filosofía a una reflexión de segundo grado, la recupera como actividad creadora de conceptos, distinta de la ciencia y de la lógica que operan por funciones, distinta también del arte que opera por percepciones y afectos. Un complemento acertado a esta reflexión filosófica serían los pensamientos producidos por un científico que ha sido capaz de enfrentarse a las tesis dominantes de los defensores de la "Inteligencia Artificial fuerte", afirmando que "debe haber algo esencial que está ausente de cualquier imagen puramente computacional», y "por encima de todos estos tecnicismos está el sentimiento de que es realmente "obvio" que la mente consciente no puede trabajar como un computador, incluso aunque mucho de lo que está realmente implicado en la actividad mental podría hacerlon (Roger Penrose (1989). La nueva mente del emperador. Oxford).

Desde una posición más claramente politica, nos encontramos con una curiosa reescritura del Manifiesto de Marx, actualizando sus líneas maestras y prolongándolas en una dirección socialdemócrata (Max Gallo (1989). Manifiesto para un oscuro fin de siglo. París), y una obra de síntesis de problemas, con multitud de datos actualizados y que voluntariamente se sitúa en la herencia intelectual de los planteamientos sesentayochistas (Ramón Tamames (1991). Un nuevo orden mundial. Madrid). Esperemos que en los próximos años vean la luz más estudios $e$ investigaciones que adopten esta perspectiva crítica y emancipadora frente al caudaloso río de desinformación y encubrimiento que tenemos que soportar en los medios masivos de comunicación.

Porque lo que tenemos que hacer es definir ya una nueva estrategia tebrica que sea capaz de generar estudios, investigaciones y programas políticos concretos desde la perspectiva en la que nos situamos.

1. Lo primero que tenemos que establecer es el "terreno de juego". Ya sabemos que la lucha se produce en todos los ámbitos en los que el sistema tiende a reproducirse como sistema de dominación. Pues, mientras que los ideólogos de los grupos dominantes (léase Fukuyama, Revel, etc.) tratan de mantener el juego en el terreno de las grandes generalizaciones, $y$ los funcionarios de la comunicación mediática nos asedian con lo empírico abstracto, de lo que se trata realmente es de huir de toda discusión en la que esté implicada la teoria.

2. El segundo paso en nuestra estrategia teórica consiste precisamente en la imperiosa tarea de reconstruir la teorta. No como una nueva "ciencia unificada", sino como un sistema complejo de conocimientos, saberes y prác- 
ticas sometido a una estrategia de argumentación comunicativa y elaborado con una finalidad emancipadora que lo provee de sentido y orientación. Tal teoría asume como procedimiento básico de construcción una metodología empírica y una epistemología materialista.

3. El tercer momento de la estrategia teórica que estamos diseñando lo constituye precisamente la reconstrucción del método. No a través de una nueva "disputa sobre el positivismo", sino mediante la producción de investigaciones concretas en los diversos ámbitos de la vida cotidiana, que, utilizando todas las técnicas cualitativas y cuantitativas apropiadas, lleguen a poner de manifiesto las vinculaciones del sistema social global con los fenómenos empíricos diarios.

El objetivo principal, a largo plazo, sería la construcción de un marco teórico explicativo de los cambios sociales. Evidentemente, este objetivo dependerá de que este programa de investigación sea capaz de suscitar diferentes grupos de trabajo en diferentes países que asuman sus planteamientos, específicamente su tratamiento interdisciplinario y una metodología abierta y creativa. Pero ese objetivo principal sólo se vuelve posible por una serie de etapas intermedias, de las cuales la que aquí presentamos sería la primera: una investigación acerca de los imaginarios sociales en cuanto constructores del orden social ${ }^{1}$.

La práctica de la investigación sociológica me ha llevado a la conclusión de que la mayor dificultad con que nos encontramos en el ejercicio de este oficio se podría resumir en una frase de larga tradición: "Hacer visible la invisibilidad social». Porque, conforme avanzamos en el conocimiento de los procesos y mecanismos que dan forma a los diferentes sistemas de relaciones sociales, más nos damos cuenta de qute existe una especie de contraftgura del sociólogo y su manía de clarificación de los procesos sociales, contrafigura que en otros tiempos se podía identificar con algo así como "sociedades secretas", "conspiradores", "sectas religiosas o satánicas", "agencias estatales de información", etc., y que ya Marx denominaba "poder social extrañon, y sus formas de aparecer como la "cosificación", el "fetichismo" o la "alienación" (justamente criticadas en cuanto a sus conexiones con una metafísica implícita, pero que sería necesario volver a estudiar después de las últimas reelaboraciones teóricas de Habermas), contrafigura, digo, que encubre vínculos, difumina evidencias y obscurece diferencias hasta conseguir que vuelva a reinar el misterio allí donde ya se habían formulado claramente los problemas, y se reinstaure el azar allí donde ya estaba establecida la norma.

1. Puede verse, en el apéndice I, un mapa conceptual de esta relación, con una breve nota explicativa. 
La primera formulación del problema consistiría, pues, en preguntarse si no es lo propio del sociólogo la tarea de descubrir el ser-construida de la realidad social, es decir, describir y hacer patentes los mecanismos y procedimientos de producción y reproducción de la realidad social denominada sociedad. Pero esta formulación sería excesivamente general y dificilmente diseñable como programa de investigación.

Si tratamos de concretar un poco más el problema, podríamos preguntarnos: "¿cómo es posible que la gente se crea las explicaciones que se suelen dar en las fuentes de información accesibles mayoritariamente sobre el por qué suceden las cosas que suceden, y qué cosas son realmente las que suceden?n Aparentemente, la cuestión sería abordable desde una sociología aplicada, la sociología de la comunicación, pero el fondo de la cuestión va mucho más ấlá, pues no se trata de un problema de "opinión pública», ni de "manipulación" de las conductas o de las conciencias, sino de una cuestión esencial para el sistema social que rige nuestras sociedades capitalistas.

Los individuos tienen que jugar según unas reglas de juego públicas y conocidas, pero los árbitros sancionan las jugadas según un reglamente diferente que sólo ellos conocen. Se construye así un referente único para unos y otros al que se denomina orden social. En torno a ese referente único se producen las luchas múltiples por definir precisamente la relación entre el conocimiento $y$ la realidad.

Mientras que en épocas anteriores a la modernidad esta definición del orden social se establecía y justificaba desde los poderes religiosos establecidos (iglesias, sectas, etc.), y las gentes la asumían como única posible y verdadera, a partir principalmente de los problemas generados por las relaciones entre la Iglesia de Roma y el Imperio ("Sacro Romano", "Sacro Germano"), y con la mediación de los primeros intelectuales que pusieron su destreza logica, escriturística y retórica al servicio del emperador, se produjeron los primeros intentos de problematizar la definición del orden social establecido como único orden posible.

Entramos así en la segunda parte del problema: ufrente al orden establecido, ¿se podría pensar en un orden alternativo?n Aquí es donde se va a abrir una variedad de planteamientos de esa posibilidad que van desde la "racional» a la "imaginativa". Porque lo que sucede en ese momento es que la organización de las relaciones sociales deja de entenderse vinculada a los poderes celestes para vincularse para siempre a los terrestres. Dicho de otra forma, el orden social deja de pertenecer a la teología, o a la metafísica, para formar parte plenamente de la historia y de su relatividad espacio-temporal.

La cuestión consiste, entonces, en especificar más exactamente las conexiones entre "orden social" y «realidad social" o "sociedad". ¿Estamos necesariamente sometidos a las definiciones de realidad de los que detentan actualmente el poder en el orden social existente? Después del fracaso histórico de determinadas utopías (el comunismo, el liberalismo, el anarquismo, etc.), ¿nos podemos permitir el lujo de plantear alternativas radicales al orden social existente? Cuestiones abiertas e importantes, pero que no forman parte 
de la línea argumental del presente escrito. Porque el problema que nos interesa es mucho más limitado y susceptible de integrar varias líneas y ámbitos de investigación empírica.

Reconocida la importancia de los elementos infraestructurales en la determinación concreta de un orden social dado, y reconocido el papel fundamental de mediación de la actividad política en la construcción de las sociedades modernas, nos interesan más bien los mecanismos por los que un determinado orden social llega a considerarse por la gente como algo natural y consiguientemente establece la dominación social como una coacción legítima, hegemónica y aceptada. De entre esos mecanismos (entre los cuales, por supuesto, se encuentran los diferentes tipos de violencia), vamos a seleccionar aqueIlos que se orientan a las creencias básicas de los individuos y que responden a un sistema complejo de racionalidades en conflicto (desde la razón instrumental a la racionalidad corporal, desde los sentimientos religiosos hasta los deseos más ocultos).

Los imaginarios sociales serian precisamente aquellas representaciones colectivas que rigen los sistemas de identificación y de integración social, y que hacen visible la invisibilidad social. Tendríamos así que el orden social que se estableció en Europa a partir de la Segunda Guerra Mundial y que ha permanecido intacto hasta finales de los años ochenta generó una serie de imaginarios sociales que permitieron la dominación pacífica en dos sistemas de orden social diferenciado, los países de sistema de democracia capitalista y los países del denominado "socialismo real" o "capitalismo de Estado", o "comunismo".

Tendríamos así una posible formulación del problema que constituye el punto de partida de nuestra investigación: "zcómo se ha vinculado el orden social a determinados imaginarios sociales en los países europeos en los últimos cincuenta años (1940-1990)", o expresado de otra manera, "zcómo se han construido los imaginarios sociales que han permitido la permanencia del orden social imperante en Europa en los últimos cincuenta años?".

Podemos pasar así a definir y delimitar los conceptos principales tal como los empleamos en esta investigación.

Cuando Durkheim afirmaba al comienzo de Las Reglas...:

Hay unas maneras de actuat, de pensat y de sentir que presentan la notable propiedad de que existen fuera de las conciencias individuales. Estos tipos de conducta o de pensamiento no sólo son exteriores al individuo, sino que están dotados de una potencia imperativa y coercitiva en virtud de la cual se imponen a aquél, quiérato o no ${ }^{2}$,

y un poco más adelante,

He aquif un orden de hechos que presencan unas caracteríscicas muy especiales: consisten en unas maneras de actuat, de pensar y de sentir, exteriores al 
individuo y que están dotadas de un poder de coacción en virtud del cual se le imponen... Constituyen una nueva especie, y es a ellos a los que debe darse y reservarse la calificación de sociales ${ }^{3}$,

tales hechos son los que van a constituir el campo de observación del sociólogo. Pero el mismo Durkheim reconoce en el Prefacio a la segunda edición de Las Reglas... que

hay casos en los que el carácrer de coacción no es fácilmente reconociblen [...], lo que tiene de especial la coacción social es que es debida, no a la rigidez de algunas disposiciones moleculares, sino al prestigio del que están dotadas determinadas representaciones ${ }^{4}$.

La lectura que Parsons realizó en La estructura de la acción social de este concepto de representaciones colectivas, y que tanta influencia tuvo en la posterior elaboración de la teoría sociológica de los años cincuenta y sesenta, vendría a reducir el sentido de "lo colectivo" a una "tenencia en común", y a plantear el problema, supuestamente metafísico, de ta separación entre la urealidad social» y sus «representaciones o manifestaciones":

Las representaciones colectivas no son, ellas mismas, la realidad social. Son representaciones de ella. [...] Pero, ¿¿dónde está la urealidad" correspondiente a la que se refieren las representaciones colectivas? Sólo observamos sus "manifestaciones" [...] pexo no observamos la "cosa misma» 5 .

No vamos a entrar ahora en la polémica de las interpretaciones, pues nos lievaría demasiado lejos. Nuestro interés consiste en señalar un punto de partida en la tradición de la teoría sociológica para enmarcar debidamente los conceptos que vamos a emplear en nuestra investigación, pensada y planteada desde la perspectiva de las discusiones actuales.

Qué sea el orden social, o cómo sea posible es una cuestión permanente desde los clásicos hasta hoy, desde Hobbes hasta Luhmann. Una muestra representativa de la dispersión de respuestas nos la da el último párrafo del capítulo que Luhmann dedica a elaborar esta cuestión.

Todo respuesta a la pregunta de cómo es posible el orden social debe ser distribuida entre diferentes teorías parciales. Se podría decir como respuesta: a través del sentido. Sc podría decir, a través de la formación de sistemas sociales, que se pudieran mantener estables durante tun tiempo en las fronteras frente a un hipercomplejo entorno. Se podría decir: a través de la evolucion sociocultural. Con cada una de esas respuestas se han indicado posteriores tareas. A pesar de todo permanece como cuestión fundamental una única cues-

3. Ibidem, p. 5.

4. Ibídem, p. xxi.

5. T. Parsons (1937), t. I, p. 452. 
tión, la problemática unidad constitutiva de una disciplina. Y esto se muestra en que las respuestas parciales toman referencias recíprocas, que tienen que ser permanentemente cooordinables unas con otras, porque cada una de eilas son incompletas e imperfectas ${ }^{6}$.

A partir de estas consideraciones, nuestra definición de orden social se ha concretado como el "marco teórico" de un programa de investigación en una serie de tesis, que paso a presentar en sus enunciados más sintéticos:

Tesis 1. El orden social no es un mero dato funcional que vincula estructuras, individuos e instituciones bajo una forma compleja de organización de la dominación, sino que también se constituye como marco de referencias epistemológicas y morales.

Tesis 2. La tendencia de todo orden social constituido hacia su permanencia y reproducción lleva consigo una exigencia de justificación más allá de las concretas situaciones históricas, y que, por tanto, le atribuya las características propias del absoluto (no sólo en cuanto legitimación cuasi-sagra$\mathrm{da}$, sino, sobre todo, como exclusión de cualquier otro orden posible como alternativa legítima al presente).

Tesis 3. Frente a esta tendencia conservadora y su pretensión de negar la dinámica histórica, surge la tendencia opuesta a recuperar aquello disperso, distelto, fragmentario, no idéntico, como memoria y promesa de la posible emancipación del orden meramente existente.

Tesis 4. En la modernidad, con el amplio desarrollo del trabajo científico aplicado cada vez a más campos de la experiencia humana, y con la reciente introducción de tecnologías que abren posibilidades aún no sospechadas, se producen renovados intentos de recuperación de la unidad, de la atadura, de la religación, bajo un orden que trata de asumir un punto de vista sobre la totalidad y ponerse a sí mismo como único posible: el orden científico. Tesis 5. La habitual cohabitación del poder y la religión en los tiempos anteriores a la modernidad, y que hoy muchos consideran como fenómeno del pasado, reaparece bajo formas emboscadas, a través de la atribución al Estado de funciones extraterritoriales y de la caracterización del poder como absoluto, mientras los contrapoderes socialmente generados permanecen en la dispersión de lo relativo cuantificable.

Tesis 6. La histórica subordinación del arte a las diversas formas eclesiásticas y laicas de religión, ha llegado a superarse en la modernidad a través de un complejo proceso de diferenciación de las exigencias de validez; mientras las diversas formas de expresión artística (que suponen un profundo trastrueque de lo material como inevitable referencia de objeto) conserven su especificidad como tal arte, podrán evitar servir a la intentada construcción de un nuevo absoluto (invisible por omnipresente) a partir de las relaciones de mercado.

6. N. Luhmann (1981a), p. 285. 
Tesis 7. La consideración materialista de la realidad no pretende elevar el fragmento "materia» a la categoría de absoluto; más bien trata de impedir que la transformación de las relaciones sociales históricas cristalice en una forma institucionalizada más del orden social, y afirmar así su consubstancial indigencia (temporalidad, contingencia, finitud, etc.), y denunciar como no verdadero cualquier inten to de establecer una totalidad histórica.

Tesis 8. Esta condición de la realidad y de nuestro conocimiento de ella nos permite activar racionalmente un programa de práctica de la esperanza en la construcción de un nuevo orden social.

Una vez que hemos dado cumplida cuenta de nuestra compresión del primer concepto de nuestro programa de investigación, tenemos que tratar de clarificar el segundo, imaginarios sociales, lo que nos introducirá también en un discurso suficientemente complejo. En primer lugar, por una razón contraria al anterior. Si el concepro de orden social ha constituido uno de los ejes cardinales de la definición de la sociología, el concepto de «imaginario social» semeja haber sido muy poco usado, y parece introducir una cierta novedad que quizás a alguien parecerá superflua.

Existen todavía en nuestras sociedades unos campos que "gozan" de amplia autonomía, precisamente porque todavía no se han constituido como uobjeto social». Su carencia de entidad objetiva, su presencia dispersa y multiforme, su enmascaramiento ideológico y simbólico han permitido que las miradas del saber y del poder no los perciban, o no lieguen a atribuirles una sustantividad suficiente como para someterlos al correspondiente proceso y procedimiento de localización institucional. Con mucha precaución, y con un cierto malestar (si se miran las posibles consecuencias), nos atreveremos a diseñar uno de esos campos que definiriamos como el propio de la praxis sociológica, el campo de los imaginarios sociales.

$\mathrm{El}$ acceso a este campo se tiene siempre de forma indirecta y a través de una ambigüedad constirutiva: no lo podemos interpretar según la lógica de una racionalidad específica, pues no se identifica con el discurso ideológico (ya que el saber del imaginario conoce su ser dependiente), ni con las racionalidades «tradicional» o "afectiva" (Weber), ni con el deseo (Foucault), y sin embargo está presente en los grandes discursos científicos, políticos, morales o religiosos como el elemento decisivo que impulsa a la acción.

Tiene que ver con las "visiones del mundo", con los merarrelatos, con las mitologías y las cosmologías, pero no se configura como arqueripo fundante sino como forma transitoria de expresión, como mecanismo indirecto de reproducción social, como sustancia cultural histórica. Aparece como opuesto al concepto en tanto que noción vaga e imprecisa no susceptible de clarificación por la dialéctica de lo abstracto y lo concreto, de lo ideal y lo material. Sin 
embargo, es resistente a cualquier tipo de ataque frontal con los instrumentos de análisis lingüístico o estadístico.

Aparece como forma imaginaria de la relación social, pero no está construido como las imágenes por la inversión y el desvanecimiento del objeto; pues su conformación tiene más que ver con los sueños diurnos que con los nocturnos $\left(\mathrm{E}\right.$. Bloch) ${ }^{7}$, y por ello está más orientado hacia el futuro que hacia el pasado. Pero también es capaz de elaborar el pasado bajo formas contrapuestas de revisión legitimadora (de los vencedores) ${ }^{8}$ o memoria subversiva (de los vencidos)?

Lo que aquí más nos interesa es su incidencia en el presente como forma de configurar, de modos y a niveles diversos, lo social como realidad para los hombres y mujeres concretos. Por eilo no se constituye como campo específico de conocimiento objetivo o de proyecciones de deseos subjetivos, sino que establece una matriz de conexiones entre diferentes elementos de la experiencia de los individuos y las redes de ideas, imágenes, sentimienros, carencias y proyectos que están disponibles en un ámbito cultural determinado.

Lo que vuelve problemático el análisis y la investigación de los imaginarios sociales es la creencia establecida de su determinación funcional y su operatividad sistémica. Cuando Parsons elabora su modelo de variables-paura se da un paso adelante en el conocimiento de determinadas funciones de los imaginarios; pero cuando ese modelo se pretende generalizar y hacer operativo para ámbitos culturales diferenciados se da un paso atrás en el conocimiento de las sociedades diferentes. Los expertos en marketing saben bien que los públicos de consumidores están segmentados de formas muy diversas, y que sólo cuando el producto está suficientemente mitificado (caso de la Coca-Cola o del Papa, por ejemplo) puede tratar de imponerse contra los imaginarios particulares de una sociedad.

Por eso no es de extrañar que se estén volviendo a emplear técnicas y modelos operativos correspondientes a sociedades del pasado (considérese el incre-

7. «Anders als der nächtliche Traum zeichner der des Tages frei wählbare und wiederholbare Gescalten in die Lufr, er kann schwärmen und faseln, aber auch sinnen und planen. Er hängt auf müssige Weise (sie kann jedoch der Muse und der Minerva nahe verwandt werden) gedanken nach, politischen, künstlerischen, wissenschaftlichen. Der Tagtraum kann Einfälle liefern, die nicht nach Deutung, sondern nach Verarbeitung verlangen, et baus Luftschlöser auch als Planbilder und niche immer nur fiktive.n E. Bloch (1959a), p. 96.

8. Un modelo cercano en el tiempo es el de la conmemoración de la Revolución Francesa (a lo largo de 1989 y que todavía "colea" en 1993 con una "imaginativa" encuesta que preguntaba a los franceses actuales sobre su conformidad con el ajusticiamiento de Luis XVI hace doscientos años...). Recordemos también los fasros de la Independencia de los EE.UU., - la más cercana celebración del V centenario de la conquista de América, y rodas las demás memorias de vencedores que aún nos aguardan en este fin de siglo.

9. Cfr. un modelo de este intento en Helmut G. Haasis (1984). Spuren der Besiegten, 3 Bde., Hamburg: Rowohlt, 1146 p., donde se trata de realizar de alguna manera el proyecto benjaminiano (cfr. W. Benjamín, [1972a], p. 180-181; ed. orig.: W. Benjamín, [1980a], I, 2, p. 695). Una interesante y reciente aportación española al tema puede verse en Retes Mate (1991). La razón de los vencidos. Barcelona: Anthropos. 
mento exponencial de los recursos retóricos más clásicos en la construcción del lenguaje publicitario). Probablemente estemos pasando de imaginarios propios de sociedades tolerantes a imaginarios que van introduciendo el modo imperativo como forma verbal de un discurso monológico ${ }^{10}$.

En cualquier caso, los imaginarios sociales tienen una función primaria que se podría definir como la elaboración y distribución generalizada de instrumentos de percepción de la realidad social construida como realmente existente. Como se comprenderá, esta función es imposible de institucionalizar, salvo en las sociedades totalitarias con censura global de los medios de información ( $y$, aún así, esas sociedades cerradas se han vuelto imposibles por la aparición de las nuevas tecnologías comunicativas). Tendríamos, por tanto que la primera función o definición de los imaginarios sociales tiene que ver con la instrumentación del acceso a lo que se considere realidad en unas coordenadas espacio-temporales específicas.

$\mathrm{El}$ momento que vivimos en nuestras sociedades burocrarizadas de consumo controlado es semejante al que se vivió en el comienzo de la modernidad, cuando se generalizó la imprenta y su producto básico, el libro. Mientras que las fuerzas de todos los anciennes régimes tratan de excluir de la nueva forma de cultura a las masas de ciudadanos, las fuerzas liberadoras, comenzando por los ilustrados, lanzan la consigna de la generalización de la educación y el establecimiento de los sistemas de enseñanza y la valoración por el mérito y no por la sangre.

En nuestras sociedades presentes se establece también una dialéctica entre los que propugnan el nuevo "panem et circensem" electrónico total (generalizar el consumo de aparatos y gadgets y alimentar al consumidor con basura cultural) y los que proponen un nuevo programa de alfabetización que incluya como materias básicas la lectura crítica de los nuevos productos culturales, el estudio de sus lenguajes, la diversificación de sus procedimientos técnicos y los procesos socioeconómicos de lucha por el control de los medios masivos de comunicación.

Pero más allá del aspecto instrumental, los imaginarios sociales proporcionan a los ciudadanos de una sociedad dada las categorías de comprensión de los fenomenos sociales. Un ejemplo hará patente lo que queremos decir. Podemos establecer con Kant que el espacio y el tiempo son uformas puras de la sensibilidad» y condición de posibilidad del conocimiento, pero las imágenes e ideas que de algún modo estaban asociadas a esas formas en la Prusia oriental de la segunda mitad del siglo XVIII pueden diferenciarse perfectamente de los imaginarios actuales sobre el espacio y el tiempo (pensemos en algo tan "evidente" como la no reversibilidad del tiempo que se encuentra problematizado por la sencilla experiencia de dar marcha atrás a una cinta de vídeo y volver a ver de nuevo algo "ya pasado"). Nuestra comprensión de lo que sucede en nuestra sociedad no puede ir más allá de los modelos de explicación que son aceptados

10. En el apéndice III exponemos las líneas generales que enmatcan nuestra metodología para tratar de superar las dificultades aqui expuestas. 
en eila; difícilmente podríamos pensar que el accidente que costó la vida a varios astronautas estadounidenses hace algunos años fuera causado por la intervención de Satanás; y viceversa, quien en el siglo XVII creyera ver volar a una mujer en una escoba no tenía más remedio que achacarlo a causas extraterrenales.

Pero los imaginarios sociales adquieren uñ grado máximo de relevancia para la teoría sociológica cuando llegan a formular las estrategias de intervención en las condiciones materiales de vida de los ciudadanos de una sociedad concreta. Este elemento del imaginario no sólo abarca el campo de la moral y de la política, sino que penetra todo el mundo de la cotidiano en lo que tiene de "saber de receras" a través de las cuales se vuelven concretas las "palabras mayores" de los discursos ideológicos.

Podríamos completar esta presentación ${ }^{11}$ con las palabras de uno de los autores actuales que con más clarividencia ha tratado la problemática de los imaginarios sociales. Me refiero a Georges Balandier y a su obra Le Détour ( $\mathrm{EI}$ desvíon), donde al tratar las relaciones entre el poder y la modernidad, concluye con un capítulo sobre "El imaginario en la modernidad":

La modernidad contemporánea no reduce el imaginario; lo segrega, como en todas las épocas; pero cambia su régimen, lo libera y lo hace más fluctuante, vuelve sus usos y su utilización más evidentes. Las sociedades que acentúan el conocimiento racional, la acción instrumental eficaz, la productividad y la expansión, intensifican sin embargo el imaginario multiplicando sus lugares y sus medios de producción, los que los utilizan y los que los manipulan. [...] Se encuentra, por una parte en estado naciente, al mismo tiempo que sometido a efectos de interferencia. Pero el aspecto más significativo es la aparición de un tecno-imaginario... ${ }^{12}$.

Y continua a lo largo de todo el capítulo precisando los diferentes tipos de imaginarios y sus diferentes ámbitos, tales como el espacio, el tiempo, los signos, los objetos, las máquinas, el hombre, etc. Los imaginarios sociales vendrían a ser aqueilos mecanismos sociales a los que alude el profesor Pérez-Agote al tratar de la "eficacia social de las ideas":

El poder simbólico o poder de producir sentido, pone en funcionamiento unas ideas que, vehiculadas a través de ciertos mecanismos sociales, logran penetrar en las cabezas de los sometidos al poder. La máxima posibilidad consiste en que aquellas ideas consigan constituirse en evidencia social, es decir, en algo que nó es puesto en tela de juicio por la simple razón de que constituye aquello "desde lo quew se interpreta, se lee la realidad ${ }^{13}$.

Se trata, por tanto, de elaborar, identificar y delimitar del modo más complejo posible una serie de algoritmos de la transformación de determinados

11. Putede verse en el apéndice II algunos textos complementatios de un reciente articulo de Raymond Ledrut.

12. G. Balandier (1985), p. 222-223.

13. A. Pérez-Agote (1989), p. 131-132. 
imaginarios sociales. En principio, nos limitatemos al ámbito europeo y af período que va desde el comienzo de la segunda guerra mundial, como momento de establecimiento del orden social que hasta ahora ha estado en vigencia $y$ ha resultado funcional globalmente para la reproducción de las condiciones de dominación y que terminaría hacia 1990 con los cambios en el Este europeo.

Se trata también de diseñar un procedimiento metodológico que emplee técnicas múltiples y diversas para captar las transformaciones en su especificidad y en sus interrelaciones. En este punto se precisa un decidido tratamiento interdisciplinario de las diversas ciencias sociales y sus técnicas propias. Pensamos que una recuperación de técnicas documentales (tal como las emplearon pioneros de la sociología, como Thomas y Znaniecki) completadas con las posibilidades que determinados programas informáticos abren a la medida, comprensión e interpretación de textos, es una tarea urgente en nuestro ámbito científico.

Finalmente, pensamos que es posible llegar a proponer una lectura interpretativa de las transformaciones culturales acaecidas en el período seńalado, y de la relación de estos cambios con la permanencia o debilitamiento de determinadas formas de dominación político-económicas.

\section{Apéndice 1. Mapa conceptual de los imaginarios sociales}

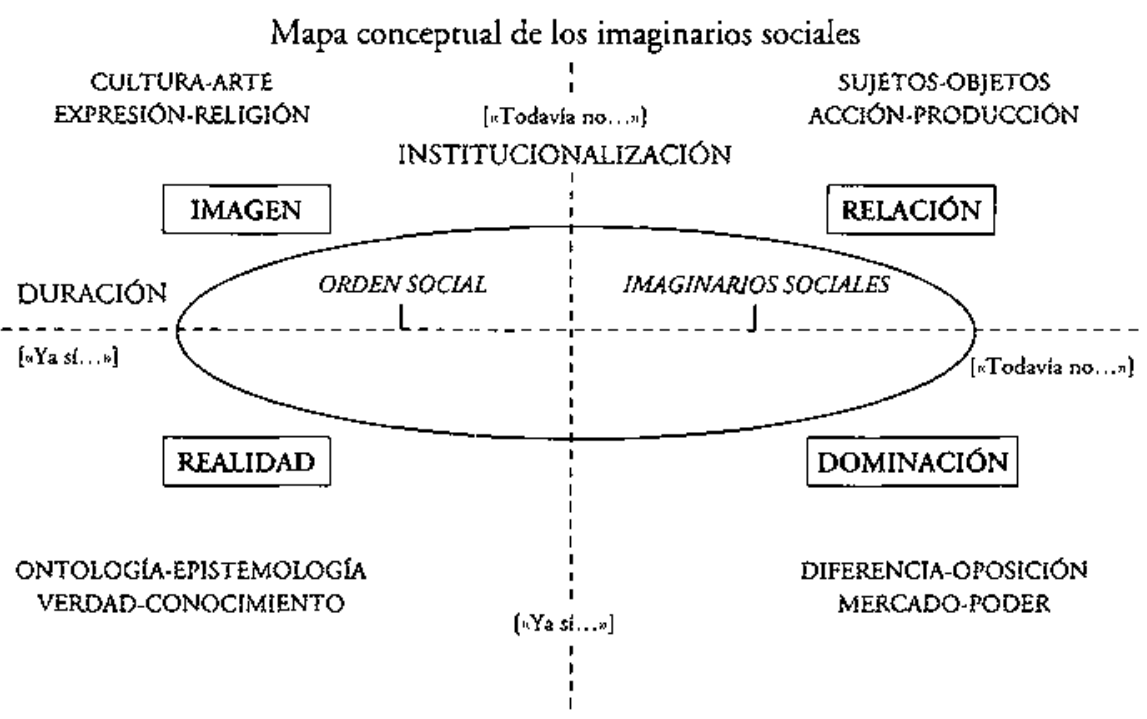

Un instrumento de gran valor pedagógico del que vengo experimentando la eficacia en los últimos tiempos son los mapas conceptuales, o esquemas basados en figuras geometricas que tratan de representar bajo las metáforas espaciales las distintas relaciones 
que establecen entre sí los conceptos en los que se expresa una idea y los ámbitos generados por esas relaciones.

En orden a clarificar las ideas exptestas en el texto vamos a sugerir como representación posible el esquema que antecede.

El esquema está formado por dos figuras geométricas superpuestas. El fondo lo constituye un eje de coordenadas que trata de representar la necesaria ubicación histórica de los imaginarios sociales. El eje horizontal definiría la inserción temporal, pero, contra to que es habitual, no establecemos un parámerro de medida con valores homogéneos continuos, sino un espacio de duración cualitativamente diferenciada que trata de superar la visión de "momentos" (discontinuos y simultáneamente existentes) que solemos significar con las denominaciones "pasado", "presente" y ufuturom. La alternativa conceptual consiste en establecer una tensión entre dos polos que representan los límites de la duración en un arco que va del "Ya no" (dura) hasta el "Todavía no" (ha entrado en la duración histórica). El eje de la espacialización trata de recubrir la misma tensión pero bajo la caracterización de la existencia institucionalizada.

Sobre ese fondo se construye una elipse cuya línea representa la totalización concreta generada desde los focos cuyos lugares son ocupados por el "Orden social" establecido y los "Imaginarios sociales" que legiriman ese orden. La figura resultante representa la diferenciación de cuatro ámbitos que vienen definidos por el establecimiento de un concepto central que se ha de entender en el horizonte de interpretación propio de cada uno de los cuatro campos. En nuestro caso consideramos que la actual totalización está construida sobre cuatro conceptos que son los de imagen, realidad, relación y dominación.

Cada uno de los cuatro cuadrantes trata de representar un ámbito de la problemática sociológica que liga el orden social con los imaginarios sociales en su propia dinámica interna y en sus concreciones históricas. Por ello, esos ámbitos vendrían marcados por diferentes conceptos que siempre tienden a comprenderse por la confrontación o el refuerzo de los que aparecen en los campos adyacentes o contrarios. Un amplio desarrollo de las relaciones y los procesos que así se establecen está en trance de elaboracion y esperamos poderlo ofrecer en breve.

\section{Apéndice II. Textos de Raymond Ledrut sobre imaginarios sociales}

En lo imaginario se pueden distinguir dos grandes categorias: la de las imágenes (o de los imaginados) y la de los imaginarios. Las imágenes son realidades "físicas" y "mentalesm que nos rodean por todas partes, sobre todo hoy: fotografias, carteles [...]. Tienen una significacion: "representan". Su realidad "física" (por lo tanto sensible y material, de materiales diversamente tratados) no haría de cllas "imágenes", si algunos sujetos no vieran ahí "algo». [...] Las imágenes no nacen solas: necesitan un productor-emisor y un receptor-espectador. [...] Entramos aquí en el terreno de lo simbblico, en sentido estricto. [...] Con las imágenes tocamos por lo tanto dos grandes dimensiones de la vida social y cultural: el atre y la religión. [...] Toda religión es "representación" (no es del orden de la racionalidad) y también puede uno atreverse a decir que toda representación es religión o religiosa.

La sociedad real sólo es real existe, mientras está tejida de imágenes que la bacen vivir.

Pero las imágenes no existen más que por los imaginarios, que constituyen el segundo sector de lo imaginario y que tienen, en cierto sentido, menos "realidad" que las 
imágenes, ya que no tienen realidad física. Ahora bien, las imágenes, cualesquiera que sean, deben su significación particular, e incluso su existencia, a los imaginarios que en cierto forma las modelan.[...] Las imágenes publicitarias nos revelan los imaginarios que utilizan, conscientemente o no, sus autores. Esos imaginarios son "arquetipos" cuyo papel es fundamental en la vida social. Cada cultura tiene los suyos - que se pueden llamar los imaginarios dominantes--, pero existen también imaginarios que atraviesan las culturas. Esos imaginarios no son representaciones, sino en cierta forma esquemas de representación. Estructuran en cada instante la experiencia social y engendran tanto comportamientos como imágenes urealesn. Su realidad es la de principios de organización que no son menos reales que otros principios de organización social cuya entera y cabal realidad se evoca con complacencia. Por lo tanto, la Sociedad de lo Imaginario - la de las imágenes y de los imaginarios - es la sociedad misma. Si se concentra uno en el término de sociedad imaginaria, se ve muy pronto que esa sociedad no es irreal, sino que por el contrario forma un elemento conscitutivo de la sociedad real. En efecto, entre los imaginarios y las imágenes hay "sociales", es decir que están unidos ellos mismos a la representación de la sociedad y de lo social. Si puede haber un imaginario e imágenes de la mujer o de la ciudad, igualmente los hay del mundo social como tal, de la comunidad y de las comunidades patticulares. Hay un imaginario de la Nación y hay también un imaginario e imágenes de la nación alemana o de la nación francesa. Pero puede haber a veces, en un grupo, imaginarios más amplios, del tipo del imaginario de la Cristiandad o del imaginario de la Humanidad.

Todos los imaginarios son los núcleos de grandes mitos. [...] La sociedad imaginaria penetra a tal punto a la sociedad real que en cierta forma la irrealiza. [...] Hay que admitir que, en buena parte, los hombres sueñan su existencia y sobre todo la existencia social. [...] Lo imaginario es ilusión y ensueño. Queda por definir el estatuto $y$ quizá la realidad de la ilusión y del ensueño. No buscando una realidad social sólida que escaparía a lo imaginario, sino tratando de captar mejor la relación de lo real y de lo irreal. Esa relación sólo puede ser establecida a nivel de la verdad. El problema no es el de la realidad de la sociedad, sino el de la verdad de lo que de ella se dice. ¿Hay una verdad de lo irreal y de la ilusión? ¿En qué consiste? [...] Incluso si hay un enlace estrecho de lo imaginario social y de la realidad social hay que tener cuidado de no confundirlos. Sin duda lo que es imaginario puede constituir una parte esencial de lo teal, pero hay que manzener, aunque sea relativizándola, la distinción de los niveles: lo imaginario no es lo real, pertenece a otro nivel. [...] Se puede al mismo tiempo admitir la continuidad y la discontinuidad en la relación de lo real y de lo imaginario. [...] j $\mathrm{Ni}$ lo real ni lo imaginario tienen estatuto estable y definitivo? [...] son movientes y transitorios. Lo que es real puede en el momento [...] siguiente volverse imaginario. Reciprocamente, lo imaginario puede convertirse en real, puede realizarse. Todo se realiza o se desrealiza, según las condiciones y el momento, según el Tiempo. [...]

Lo imaginario es un modo de ser de una esencia que no ha llegado todavía a la existencia o que ha perdido la existencia. Lo real, en el sentido fuerte, es la existencia radical y sustancial. Es la unidad del interior y del exterior, su apariencia coincide con su estructura interna. Se nota entonces que lo imaginario no ha alcanzado todavía esa plena y entera sustancialidad. Es, tal vez, una realidad que se está constituyendo, o en vías de deshacerse, una "forma" en parto o en decadencia, y si participa de la irrealidad, participa más o menos de la realidad. [...]

Lo teal es proceso y no estado. [...] Lo imaginario social, además de su funcionalidad bien real, puede ser algo real que todavía no es o que ya no es, algo superado [...] o posible [...]. Lo imaginario de lo social (la sociedad imaginaria) es un modo de 
realidad de los posibles de la sociedad. Lo mismo que el estado es una dimensión de lo real (y el estado de la realidad social), asimismo lo posible es otra dimensión. El mundo de lo imaginario es el de lo que ya no es (Never more) o todavía no es. La sociedad imaginarta es pues efectivamente la doble dimensión temporal (histórica) de la sociedad real. [...] Si una dimensión de la realidad es la coacción, ésta nunca es un dato en bruto, es tomada en un movimiento y un proceso. La coacción sólo aparece como tal según la libertad y lo imaginario. Y podría decirse que la tecíproca es también cierta: ninguna imagen y ningún imaginario puede evadirse completamente de la dimensión de coacción de lo real.

Existe pues una dialéctica cierta de lo real y de lo imaginario. La sociedad imaginaria asedia constantemente a la sociedad real (la del presente) que se hundiría si no fuese así. Y la sociedad real pesa sobre todos los desarrollos de lo imaginatio. Lo real pesa en lo imaginario y lo imaginario en lo real. [...] Naturalmente, la realidad social puede cesar de ser historica, puede detenerse y fijarse o caer en lo inesencial. No es sin embargo su ley. Su ley es la de la autoconstinución de la realidad social. La sociedad real nunca es como tal dada definitivamente: lo que en ella es dado no puede serlo y parecerlo más que como transitorio o transición. La sociedad real que no fuese transitoria dejaría de ser una sociedad humana, o sea una sociedad: una sociedad real. La sociedad imaginaria no puede situarse fuera de la sociedad real: participa por el contrario de su autoconstitución. Le es consustancial. Así, lo real engendra lo imaginario y lo imaginario engendra lo real. La saciedad real porque se realiza necesita desrealizarse: los dos movimientos de realización y desrealización está íntimamente asociados. Hay que evitar por lo tanto la idolatria "metafísica" que quisiera poner los seres y el ser de una vez por todas. Lo imaginario pertenece al proceso de constitución de la realidad social. [...]

Existir para una sociedad es inventarse en permanencia [...]. La invención social es debida profundamente y por una parte esencial al "trabajo" de lo imaginatio colectivo. Una parte importante de las actividades "imaginantes" o imaginativas está dedicada a la búsqueda de soluciones a problemas de fines y de valores (no de medios: to cual es una ocupación intelectual). [...] Hay que ensayar las soluciones y no en la realidad todavía sino mucho antes en el sueño, en lo imaginario. Las imágenes y los imaginarios nuevos no son reglas de acción real, sino modelos de acciones posibles. Esos posibles serán, o no, experimentados o practicados. Con anterioridad son imaginados. [...]

Lo imaginario es doble, dual o dúplice. Se sitúa en el terreno de lo posible concreto. Expresa la realidad de lo posible. Pero esta realidad es paradójica, puesto que lo posible no es lo real por definición. La realidad de lo posible no puede ser más que una manera de vivirlo, lo que quiere decir que reside en la simulación. [...] Lo imaginario está situado entre lo real y lo irreal y más bien los junta, los une.[...] El mimetismo se parece a la simulación excepto en que es totalmente ureal", mientras que todo lo imaginario participa de lo irreal: no copia ni imita lo real más que para desrealizarlo o irrealizarlo. Imaginar no es imisar. [...]

Quiérase o no lo imaginario tiene que ver con la creencia y la fe. Acaba uno por amar apasionadamente lo irreal como tal, es decir porque es irrealy en tanto que lo es. [...] Si, en una sociedad, las imágenes y los imaginarios son tomados por lo que son, es decir incitaciones a la invención de una sociedad "real", no pueden "engañar" a nadie. Pero cuando lo imaginario por el contrario no está desarrollado o realizado en la acción y en la vida no es más que fantasma o fantasmas, irrealidad. [...] La génesis de una imagen o de un imaginario, no proporciona medio alguno de saber si es perfectamente ilusorio y condenado a la "degradación" religiosa por no poder dar nacimiento a una acción y a una realidad. [...] 
La función equilibradora de lo imaginario es según G.Durand triple: equilibraje biológico, equilibraje sociológico, equilibraje cósmico-religioso (escos términos son míos). Pero, además de que ese equilibraje es muy frecuentemente una racionalización culrural de las relaciones de fuerzas en la sociedad real, es cierto que lo imaginario puede ser también un factor de desequilibraje. [...] La función de desequilibraje de lo imaginario es paradojicamente ( $y$ a través de su misma negatividad) una función de realización. Lo imaginario equilibrador por el contrario desrealiza en las imágenes justificadoras; fantasmagoriza y embellece.

Raymond LeDRUT, "Société réelle et société imaginaire", en Cabiers Internationaux de Sociologie, 82 (1987) 41-52.

\section{Apéndice III. Propuesta metodológica}

La investigación que estamos proponiendo, y que, en parte, ya hemos comenzado a realizar, utiliza todo tipo de métodos, lo mismo cualitativos que cuantitativos, para conseguir los objetivos planteados. Somos conscientes de que, también en este terreno de la metodología, se está produciendo una enorme transformación de los conceptos, las teorías, los modelos y las aplicaciones operativas. Ello no obstante, nuestra práctica metodológica concreta trata de emplear todas las técricas disponibles para conseguir los objetivos propuestos en cada caso.

Unas breves líneas bastarán para describir el procedimiento de búsqueda que seguimos en las investigaciones particulares. El primer paso consiste en establecer las conexiones fundamentales del objeto de investigación considerado como un sistema; consiste, por tanto, en definir la totalización de la que partimos (quizás se podría también denominar el "discurso ideológicom dominante acerca del objeto de investigación). El segundo momento es el analítico, y ello en tres niveles: el temporal, el de la temática y el de los indicadores o instrumental; correspondientemente a la terminología anterior, éste sería el momento de la destotalización. El tercer momento, que es cuando se produciría, como resultado del proceso, un conocimiento suficientemente válido y fiable del objeto de investigación, sería el de la nueva conceptualización compleja en la que se incluirian todos aquellos elementos ignorados por el tópico, desgastados por la ideología, excluídos por la experiencia y la vivencia concreta; con ello se produciría un tercer momento necesario para el conocimiento de retotalización.

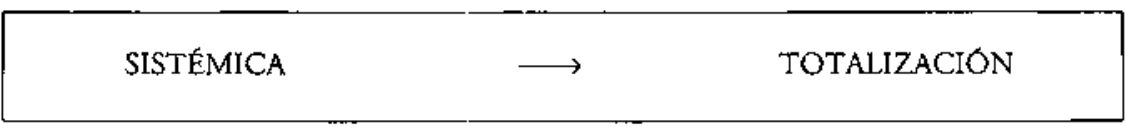

\begin{tabular}{|c|c|}
\hline $\begin{array}{l}\text { ANALITICA } \\
\text { - Temporal } \\
\text { - Temática } \\
\text { - Instrumental }\end{array}$ & DESTOTALIZACION \\
\hline
\end{tabular}


Comprendemos que la desnudez de este esquema no dejará de suscitar cuestiones al lector interesado en el tema. No podemos aquí ni siquiera iniciar un discurso metodológico que pueda dar cuenta de las nuevas técnicas y enfoques que la práctica de la investigación sociológica nos lleva a poner por obra. En una próxima publicación, en la que se expondrán los tesultados de una de nuestras investigaciones empíricas, abordaremos más detenidamente esta cuestion ${ }^{14}$.

\section{Apéndice IV. Propuestas de ámbitos concretos de investigación}

0. Partimos para nuestras investigaciones de la relevancia de lo cotidiano para captar, comprender y promover las transformaciones del orden social. Sin embargo, nuestra consideración de la vida cotidiana (lo mismo en el ámbito privado que en el ámbito público) no se desliga de sus relaciones al sistema social y de las mediaciones que esa relación implica.

[A] Desde esta perspectiva, tomamos como ámbito más obvio, en primer lugar, la vivienda y lo que en ella acontece. Desde la materialidad de la construcción, distribución de espacios, asignación y usos de los mismos, decoración, utillaje (muebles, sistemas energéticos, electrodomésticos, etc.), hasta las acciones que en ella tienen lugar: higiene, comidas, formas de trabajo y de descanso, secuencias temporales individuales y comunes, individuos que viven establemenre, visiranres (formas y tipos de visita), fórmula legal de asentamiento en la vivienda (propiedad, arrendamiento, etc.), y las variaciones que estos elementos han sufrido en los últimos cincuenta años.

[B] Dando un paso más en nuestra búsqueda, nos encontraríamos con la ciudad (pueblo, aldea, barrio, metrópolis) como hábitat. Igualmente, nos interesan aquf los aspectos más materiales (diferenciaciones en los diversos tipos de agrupamiento de viviendas, zonas dedicadas a las distintas funciones sociales, vías de comunicación y medios (distancias, tiempos, formas, etc.), análisis de la ciudad como "texto" (lectura semiótica) y, por supuesto, las acciones realizadas por los individuos, usos reales de los espacios, diferenciación de las secuencias horarias (¿đónde está la gente? ¿a qué hora? ¿qué hace? ¿durante cuanto tiempo?, etc.), y las variaciones de todo ello.

[C] La base material a partir de la cual son posibles las observaciones acerca de los humanos es, evidentemente, el cuerpo, la estructura corporal, la corporeidad o modo de existencia humano en el espacio y el tiempo. La historia humana encierra una enorme riqueza acerca de la cultura del cuerpo y la consideración del cuerpo en la cultura. En este terreno nos encontramos, por un lado, con una valoración positiva en el fenómeno del deporte moderno y todo lo que en torno a él se construye socialmente y, por otro, una valoración negativa en todo lo que tiene que ver con el fenómeno de la locura y todos los elementos jurídicos, institucionales y sociales que la definen como núcleo ocul to de la articulación social.

[D] Hay algunas actividades humanas que nos patecen especificamente interesantes para el objeto de nuestra investigación, y en las que es más patente la transformación que están sufriendo los imaginarios sociales. La primera de ellas es la

14. Para una aproximación más actualizada a las cuestiones metodologicas debe consultarse Pintos (1994a). Sociocibernética: marco sistémico y esquema conceptual. 
determinación de lo que es trabajo, sus formas y sus sujeros. En paralelo con ello, hay que delimitar también to que se considera ocio, o tiempo, o formas ajenas al trabajo, que aparece también como un elemento muy significativo de cambio.

[E] En este contexto hay que situat el ámbito de la fiesta y to festivo. No interesa tanto como algo sustantivo, sino en su relación a lo cotidiano y las formas de ruptura del mismo, por eso tampoco se puede asimilar concretamente con la idea de ocio o de vacatio, sino, sobre todo, con la idea de celebración (qué es el acontecimiento que se celebra, por qué [sentido de la celebración], formas privadas y públicas de hacer las fiestas, tipos distintos de fiestas). Y sus variaciones.

[F] Una forma peculiar de comportamiento que conjuga el ocio con lo festivo es el ámbito del juego. Habría, por tanto, que investigarlo específicamente pues su complejidad ha crecido en los últimos decenios. Nos interesan los espacios, instrumentos, reglas, tipos, participantes. En concreto, sería esclarecedora una investigación que siguiera los pasos de las transformaciones de los juguetes.

[G] El principal juego al que jugamos, casi sin darnos cuenta, es el ujuego de la vida». Un elemento básico de ese juego es el que nos interesaría aquí, y es el que supone las formas de relación entre las personas. Así como el desarrollo biológico, psíquico y mental de los individuos sigue unos determinados códigos de difícil exclusión, sus formas de relación con sus semejantes se construyen sobre códigos sociales, muchas veces ocultos y extremadamente rígidos, otras veces laxos e imprevisibles. Nos interesa conocer la configuración de esos códigos y sus diferenciaciones (noviazgos, matrimonios, familia, amistades, parentela, colegas, cofrades, camaradas, compañeros, etc.).

[H] Hay unas formas especificas de códigos sociales que solemos denominar roles, y que representan el conjunto de conductas, actitudes e ideas que podemos esperar de determinados tipos de personas. Aquí nos interesarla investigar las variaciones en los roles atribuidos a los sexos y a las etapas de la vida (infancia, juventud, vejez, etc.). Lo que interesa es delimitar dos cuestiones: la primera, las variaciones que las sociedades introducen en la definición de los roles; la segunda, las diferencias en la percepción e identificación de los individuos con esos roles.

[I] Las relaciones de la vida cotidiana con el sistema social vienen mediadas por los sistemas e instrumentos de comunicación. Establecer las variaciones y el sentido de las mismas en el uso de la comunicación entre las personas (cartas, teléfono, periódicos, tecnologías informáticas, etc.) sería necesario para definir con precisión cómo se sitúan los individuos en las redes comunicativas, su acceso a la mercancía información y su capacidad de intervención.

[J] La subordinación de las relaciones económicas y políticas a los aspectos comunicacionales, tal como progresivamente se está estableciendo en los países occidentales, exige un cuidadoso análisis de los productos culturales. A través de ellos se trata de incidir en el mantenimientos, creación y destrucción de los imaginarios sociales. Por ello, es necesario establecer las líneas generales de la producción de imaginarios sociales previa a la consideración de la cultura como mercancía. Ello nos obligará a tratar analíticamente el proceso de producción y consumo de imaginarios religiosos y políticos, como la función primordial de instituciones como las Iglesias y los Estados.

[K] Es precisamente el momento temporal del que arranca nuestra investigación (segunda guerra mundial), en el que se puede siruar el punto de partida de la generación de los nuevos imaginarios. Generación que tiene como vehículos prin- 
cipales el cine y la música. Pero eso habría hoy que generalizarlo a las formas literarias (novelas, poesía, teatro, best-sellers, etc.), a las formas audio-visuales (disco, vídeo, fotografía, infografia, etc), sin olvidar el amplio campo de los medios masivos de comunicación, que tratan de asumir las funciones eclesiásticas y politicas en la construcción del mercado cultural.

\section{Bibliografia}

ADORno, T.W. (1970). Teoria estética. Madrid: Taurus, I971, 479 p.

Balandier, Georges (1985). Le détour. Pouvoir et modernité. París: Fayard, 1985, 271 p.

- (1987). "Images, images, images", en Cabiers Internationaux de Sociologie, núm. 82 (1987) p. 7-22.

BACz.Ko, Bronislaw (1991). Los imaginarios sociales. Memorias y esperanzan colectivas, Buenos Aires: Nueva Visión, 1991, 200 p.

BarTHes, Roland (1964). Essais critiques, París: Seuil, 1981, 281 p.

- (1982). Lo obvio y lo obtuso. Imágenes, gestos, voces. Barcelona: Paidós, 1986, 381 p.

- (1986). El susurro del lenguaje. Más allá de La palabra y de la escritura. Batcelona: Paidos, $1987,357 \mathrm{p}$.

BeNjAMin, Walter (1980). Gesammelte Schriften: $1-$ VII, 17 vols. Frankfurt: Suhrkamp, 1980-1989.

BERGER, Peter L. \& LUCKMANN, Thomas (1966). La construcción social de la realidad. Buenos Aires: Amorrortu, 1976, 235 p.

BeRGSON, Henri (1896). Matière et mémoire. Essai sur la relation du corps á l'esprit. París: Félix Alcan, 1925,280 p.

Btoch, Ernst (1935). Erbschafi dieser Zeit. Erweiterte Ausgabe. Frankfurt: Suhrkamp, $1992,415 \mathrm{p}$.

- (1959). Das Prinzip Hoffnung, (in drei Bänden). Frankfurt. Suhrkamp, 1969, 1657 p. (hay traducción al castellano: Madrid: Aguilar).

- (1969). Philosophische Aufsätze zur objektiven Phantasie. Frankfurt: Suhrkamp, $1985,634 \mathrm{p}$.

Bourdieu, Pierre (1980). El sentido práctico. Madrid: Taurus, 1991, $453 \mathrm{p}$.

BroNOWSKI, Jacob (1979). Los origenes del conocimiento y la imaginación, Barcelona: Gedisa, 1981, 152 p.

Casroriadis, Cornelius (1975). L'institution imaginaire de la société. París: Seutil, 1975 , 505 p. (traducción al castellano: 2 vols., Barcelona: Tusquets, 1989).

Certeau, Michel de, (1974). La culture au pluriel. París: Union Générale d'Éditions, $1974,313 \mathrm{p}$.

-- (1980). Linvention du quotidien I: Arts de faire. París: Gallimard, 1990, 350 p.

ChateAU, Jean (1972). Les sources de limaginaire. París: Editions Universitaires, 1972, $320 \mathrm{p}$.

CoRbin, Alain (1982). Le miasme et la jonquille. L'odorat et limaginaire social XVIIIXIX siedcles. París: Flammarion, 1993, 336 p.

- (1988). Le territoire du vide. L'Occident et le desir du rivage (1750-1840). París: Flammarion, 1990,407 p. (hay traducción al castellano).

DlBORD, Guy (1971). La sociedad del espectáculo. Madrid: Castellote, 1976, $155 \mathrm{p}$.

Deleuze, Gilles \& GuatTart, Felix (1980). Capitalisme et schizofrenie. Mille Plateaux, París: Minuit, 1980,645 p. (hay craducción al castellano).

- (1991). Qu'est-ce que la philosophie? París: Minuit, 1991, 208 p. 
Delévze, Gilles (1983). Cinéma 1. L'źmage-mouvement, París: Minuit, 1983, 298 p.

- (1985). Cinéma 2. L'image-temps, París: Minuit, 1985, 379 p.

- (1990). Pourparlers, París: Minuit, 1990, 250 p.

DURAND, Gilbert (1960). Las estructuras antropológicas de lo imaginario. Madrid: Taurus, $1981,454 \mathrm{p}$.

- (1968). La imaginación simbblica. Buenos Aires: Amorrortu, 1971, 147 p.

DURKHEIM. E., (1895). Les règles de la methode sociologique, París: PUF, 1968 , 149 p.

- (1912). Les formes élementaires de la vie religieuse. París: PUF, 1968, 648 p. (hay traducción al castellano en varias editoriales: Akal, Alianza, etc.).

Duvignaud, Jean y otros (1976). Les imaginaires. París: Union Générale d'Éditons, $1976,446 \mathrm{p}$.

Francastel, Pierre (1965). La realidad figurativa: I y II. Barcelona: Paidos, 1988, 253 y $573 \mathrm{p}$.

GARAGALZA, Luis (1990). La interpretación de los símbolos. Hermenéutica y lenguaje en la filosofia actual. Barcelona: Anthropos, 1990, $206 \mathrm{p}$.

Godel.rer, Maurice (1984). Lo ideal y lo material. Madrid: Taurus, 1989, 308 p.

Goffman, Erving (1959). La presentación de la persona en la vida cotidiana. Buenos Aires: Amorrortu, 1971, 273 p.

GOMEZ DE LIAÑo, Ignacio (1982). El idioma de la imaginación. Ensayos sobre la memoria, la imaginación y el tiempo. Madrid: Tecnos, $1992,483 \mathrm{p}$.

- (1989). La mentira social. Imagenes, mitos y conducta. Madrid: Tecnos, 1989, 269 p.

GONZAIEZ REQUENA, Jesús (1989). El espectáculo informativo o la amenaza de lo real. Madrid: Akal, 1989.

Gumbracht, H.U. \& Pferffer, K.L. (Hrsg.) (1991). Paradoxien, Dissonanzen, Zusamenbrüche. Situationen offener Epistemologie. Frankfurt: Suhrkamp, 1991, 863p.

HABERMAS, Jürgen (1962). Historia y critica de la opinión puiblica. Barcelona: Gustavo Gili, 1981, 351 p.

- (1963). Tearia y Praxis. Madrid: Tecnos, 1987, $439 \mathrm{p}$.

- (1981a). Teoría de la acción comunicativa; I.Racionalidad de la acción instrumental. Madrid: Taurus, 1987, $517 \mathrm{p}$.

- (1981b). Teoría de la acción comunicativa: 2. Critica de la razón funcionalista. Madrid: Taurus, $1987,618 \mathrm{p}$.

HeidegGer, Martin (1950). Holzwege. Frankfurt: Klostermann, 1950, 345 p.

HUARTE DE SAN JUAN, Juan (1575/1594). Examen de ingenios para las ciencias. Madrid: Cátedra, $1989,725 \mathrm{p}$.

Huizinga, Johan (1938). Homo ludens. Essai sur la fonction sociale du jeu. Paris: Gallimard, 1988, $341 \mathrm{p}$.

Hussert, Edmund (1923). "Eine Möglichkeit und Phantasie". En Phantasie, Bildbeurustsein, Erinnerung, Husserliana, Band XXIII. The Hague: Martinus Nijhoff, 1980 , p. 546-564.

- (1936). "Die Krisis der europiaischen Wissenschaften und die transcendentale Phänomenologie, (Husserliana, VI)n, En Gesammelte Schriften, Bd. 8. Hamburg: Felix Meiner, 1992, 276 p.

IBANEZZ, Jesús (1985). Del algoritmo al sujeto. Perspectivas de la investigación social. Madrid: Siglo XXI, 1985, 365 p.

- (Ed.). (1990). Nuevos avances en la investigación social. La investigación social de segundo orden. Barcelona: Suplementos Anthropos, núm. 22, 1990, 200 p.

- (1992a). El regreso del sujeto. La investigación social de segundo orden. Madrid: Siglo XXI, 1994, $193 \mathrm{p}$. 
- (1992b). "Residuos imaginarios y simbólicos". En Archipielogo, núm. 10-11, 1992, p. 173-182.

- (1993). «El centro del Caos". En Archipielogo, núm. 13, 1993, p. 14-26.

- (1994). Por una sociologia de la vida cotidiana. Madrid: Siglo XXI, 1994, $305 \mathrm{p}$.

IMBERT, Gérard (1990). Los discursos del cambio. Imagenes e imaginarios sociales en la España de la Transicion. Madrid: Akal, 1990, 204 p.

Jameson, Fredric (1991). Postmodernism or, the Cultural Logic of Late Capitalism. Londres: Verso, 1991, $439 \mathrm{p}$.

Jung, Carl Gustav (1953). Arquetipos e inconsciente colectivo. Buenos Aires: Paidos, 1970, $182 \mathrm{p}$.

KAMPER, Dietmar (1981). Zur Geschichte der Einbildungskraft. Reinbek: Rowohlt, $1990,302 \mathrm{p}$.

KAMPER, Dietmar (1986). Zur Soziologie der Imagination. Munich: Carl Hanser, 1986, $216 \mathrm{p}$.

KEANE, John (1984). Public life and late capitalism. Toward a socialist theory of democracy. Cambridge: CUP, 1984, $340 \mathrm{p}$.

KEARNEY, Richard (1988). The Wake of Imagination. Ideas of creativity in Western culture. Londres: Hutchinson, 1988, $467 \mathrm{p}$.

- (1991). Poetics of Imagining. From Husserl to Lyotard. Londres: Harper Collins, $1991,234 \mathrm{p}$.

KogAN, Jacobo (1986). Filosofia de la imaginación. Función de la imaginación en el arte, la religion y la filosofia. Buenos Aires: Paidos, $1986,270 \mathrm{p}$.

LAPLANTINE, François (1974). Las voces de la imaginación colectiva. Mesianismo, posesion y utopia. Barcelona: Gedisa, 1977, 216 p.

LASH, Scott \& FrIEDMan, Jonathan (Eds.) (1992). Modernity of ldentity. Oxford: Blackwell, 1992, 380 p.

LECHNER, Norbert (1986). La conflictiva y nunca acabada construcción del orden deseado. Madrid: CIS/Siglo XXI, 1986, 179 p.

LEDRUT, Raymond (1987). "Societé réelle er société imaginaire». En Cahiers Internationaux de Sociologie, núm. 82 (1987) p. $41-52$.

LefEgVRE, Henti (1980). La presencia y la ausencia. Contribucion a la teoria de las representaciones. México: FCE, 1983, $279 \mathrm{p}$.

LIPOVETSKY, Gilles (1983). La era del vacio. Ensayos sobre el individualismo contemporáneo. Batcelona: Anagrama, 1990, $221 \mathrm{p}$.

LOPEZ SANCHEZ, Pere (1993). Un verano con mil julios y otras estaciones. Barcelona: de la Reforma Interior a la Revolucion de Julio de 1909. Madrid: Siglo XXI, 1993, 286 p.

LOVENICH, Friedhelm (1990). Paradigmenwechsel. Über die Dialektik der Aufklärung in der revidierten Kritischen Theorie. Würzburg: Königshausen, 1990, 290 p.

Lowe, Donald M. (1982). Historia de la percepción burguesa. México: FCE, 1986, $323 \mathrm{p}$.

Luhmann, Niklas $(1980,1981,1989)$. Gesellschaftstruktur uns Semantik. Studien zur Wissenssoziologie der Modernen Gesellschaft. Frankfurt: Suhrkamp, 3 vols., 1980, $1981,1989,319,294$ y 458 p.

- (1984). Liebe als Passion. Zur Codierung von Intimität. Frankfurt: Suhrkamp, 1984, $231 \mathrm{p}$.

- (1988). Erkenntnis als Konstruktion. Berna: Benteli, 1988, 74 p.

- (1991). Soziologie des Risikos. Berlín: Walter de Gruyter, 1991, 252 p. (hay traducción al castellano). México: Universidad Iberoamericana/Universidad de Guadalajara, 1992, 285 p.) 
- (1992). Beobachtungen der Moderne. Opladen: Westdeutscher, $3^{\text {a }}$ ed., 1992, $220 \mathrm{p}$.

LYOTARD, Jean-François (1979). La condition postmoderne. Rapport sur le savoir. París: Minuit, 1983, 109 p. (hay traducción al castellano).

Luinares, M. del Mar (1990). Mouros, ánimas, demonios. El imaginario popular gallego. Madrid: Akal, 1990, 207 p.

Maffesoli, Michel (1976). Logica de la domination. Barcelona: Península, 1977, $244 \mathrm{p}$.

- (1988). El tiempo de las tribus. El declive del individualismo en las saciedades de masas. Barcelona: Icaria, 1990, $284 \mathrm{p}$.

- (1993). "The Social Imaginary (Trend Reporc)». En Current Sociology, vol. 41, núm. 2 (otoño de 1993), p. 1-107.

MaLRIEU, Philippe (1971). La construcción de lo imaginario. Madrid: Guadarrama, $1971,286 \mathrm{p}$.

Marín, Louis (1973). Utópicas: juegos de espacios. Madrid: Siglo XXI, 1975, 313 p.

Marramao, Giacomo (1983). Poder y Secularizacion. Barcelona: Península, 1989, $301 \mathrm{p}$.

MarX, Karl (1844). Manuscritos de Paris. Escritos de los "Anuarios Francoalemanes" (1844) (OME-5). Barcelona: Critica, 1978, $468 \mathrm{p}$.

- (1953). Die Frühschriften, Sturtgart: Kröner, 1968, 588 p.

Mate, M. Reyes (1991). La razón de los vencidos. Barcelona: Anthropos, 1991, $238 \mathrm{p}$.

MatTelaRT, A.; Delcourt, X. \& MATtelart, M. (1984). La culture contre la démocratie? L'audiovisuel á l'heure transnationale. París: La Découverte, 1984, $224 \mathrm{p}$.

Merleau-Ponty, Maurice (1945). Phénoménologie de la perception. París: Gallimard, $1963,531 \mathrm{p}$.

MrTrY, Jean (1984). Estética y psicologja del sine, 2 v. Madrid: Siglo XXI, 1989, $1002 \mathrm{p}$.

- (1990). La semiologia en tela de juicio. Cine y lenguaje. Madrid: Akal, 1990, 166 p.

MORiN, Edgar (1962). L'esprit du temps. Paris: Grasset, 1983, 288 p.

- (1973). El paradigma perdido, el paratso olvidado. Ensayo de bioantropologia. Barcelona: Kairós, 1978, 266 p.

- (1982). Ciencia con consciencia. Batcelona: Anthropos, 1984, 376 p.

- (1986). El método, III: El conocimiento del conocimiento. Madrid: Cátedra, 1988, $263 \mathrm{p}$.

- (1991). El método N: Las ideas. Madrid: Cátedra, 1992, 267 p.

MOUzELIS, Nicos P. (1991). Back to Sociological Theory. The construction of Social Orders. Londres: MacMillan, 1991, 214 p.

MUMFORd, Lewis (1961). La cité a travers l'histoire. París: Seuil, 1964, 784 p. (edición original en inglés; hay traducción al castellano en Buenos Aires: Infinito).

PARSONS, Talcott (1937). La estructura de la acción social. Madrid: Guadarrama, 1968, 2 vols., $982 \mathrm{p}$.

Passeron, J.-C. (1990). L'usage faible des images, en XII CMS. Madrid: 1990, 21 p.

Pérez-Agote, Alfonso (1989). La sociedad y lo social. Ensayos de sociologia. Bilbao: Universidad País Vasco, 1989, $177 \mathrm{p}$.

Pintos, Xoan-Luis (1981). "Conflicto de racionalidades". En Agora, I (1981) p. $65-83$.

- (1986). «Saber y sentido (Lectura y metáfora de un tema escondido en la obra de 
M. FoucaulT)". En R. Máiz (comp.). Discurso, poder, sujeto. Lecturas sobre Michel Foucault. Universidad de Santiago de Compostela, 1986, p. 13-43.

- (1988a). "Ciudad, información y poder (Vtejas y nuevas consideraciones sobre las funciones históricas de las ciudades)". En R Villares (coord.). La ciudad y el mundo urbano en la historia de Galicia. Santiago de Compostela: Tórculo, 1988, p. 13-34.

- (1988b). "Para unha crítica da tecnocracia na "sociedade da información». En Ingenium, I (1988) p. 165-190.

- (1990). Las fronteras de los saberes. Madrid: Akal, 1990, $318 \mathrm{p}$.

- (1993). "El imaginario social de la religión (Perspectiva desde Galicia)". En O feito relixioso na Historia de Galicia. Santiago de Compostela: AGH, 1993, p. 175-199.

- (1994a). "Sociocibernética. Marco sistémico y esquema conceptual". En J.M. Delgado \& J. Gutiérrez (Eds.). Métodos y técnicas cualitativas de investigacion en ciencias sociales. Madrid: Síntesis, 1994, p. 563-580.

- (1994b). «El imaginario Católicon. En J.A. Gimbernat \& C. Gomez (Eds.). La pasion por la libertad. Homenaje a I. Ellacuria. Estella: Verbo Divino, 1994, p. $103-123$.

- (1994c). "El puño y la espada. Los imaginarios sociales de la violencia». En La balsa de la medusa, núm. 29 , p. 35-48.

REQUENA, Miguel (1984). "Las respresentaciones colectivas en los pueblos indoeuropeos". En RE/S, núm. 25, p. 181-195.

Ricoeur, Paul (1986). Ideología y Utopia. Barcelona: Gedisa, 1989, 355 p.

RoChBerg-Halton, Eugene (1986). Meaning and Modernity. Social Theory in the Pragmatic Attitude. Chicago: Chicago Press, 1986, 299 p.

SALAMAN, Graeme (1980). "Organizations as constructors of social reality (II)". En G. Salaman \& K. Thompson (Ed.). Control and Ideology in Organizations. Milton Keynes: The Open University Press, 1980, p. 237-256.

SAMI-ALJ (1991). L'espace imaginaire. París: Gallimard, 1991, 265 p.

SARTre, Jean-Paul (1940). L'imaginaire. Pyychologie phénoménologique de l'magination. París: Gallimard, 1982, 375 p.

- (1960). Critique de la ratson dialectique (précédé de Questions de méthode). T.I: Théorie des ensembles pratiques. Paris: Gallimard, 1967,757 p.

- (1985). Critique de la raison dialectique. T.II (inachevé): L'intelligibilité de l'Histoire. París: Gallimard, 1985, 469 p.

Schmidt, Siegfried J. (Hg.). (1987). Der Diskurs des Radikalen Konstruktivismus. Frankfurt: Suhrkamp, 1987, 476 p.

- (1992). Kognition und Gesellschaft. Der Diskurs des Radikalen Konstruktivismus núm. 2. Frankfurt: Suhrkamp, 1992, 456 p.

Seidman, S. \& WAGNER, D.G. (Eds.) (1992). Postmodernism and Social Theory. Oxford: Blackwell, $1992,379 \mathrm{p}$.

SENNET, Richard (1970). Vida urbana $e$ identidad personal. Los usos del desorden. Bercelona: Península, 1975, 208 p.

SiMmel, Georg (1908). Sociología. Estudios sobre las formas de socialización. Madrid: Revista de Occidente, $1977\left(2 .^{2}\right.$ ed.). 2 vols., 808 p. (Actualmente teimpresa en Alianza).

- (1911). Sobre La aventura. Ensayos filosóficos. Barcelona: Península, 1988, 287 p.

- (1957). El individuo y la libertad. Ensayos de critica de la cultura. Barcelona: Penfonsula, $1986,285 \mathrm{p}$.

ThOMpson, John B. (1992). Ideology and Modern Culture. Critical Social Theory in the Era of Mass Communication. Cambridge: Polity, 1992, 362 p. 
THOMPSON, Kenneth, (1980). "Organizations as constructors of social reality (I)". En G. Salaman \& K. Thompson (Ed.). Control and Ideology in Organizations. Milton Keynes: The Open University Press, 1980, p. 216-236.

Tortosa, José M. (1992). Sociología del sistema mundial. Madrid: Tecnos, 1992, $172 \mathrm{p}$.

TRONE, Aldo (1989). Ensoñación e imaginario. La estética de Gaston Bachelard. Madrid: Tecnos, $1989,139 \mathrm{p}$.

VARELA, Francisco J. (1988). Conocer. Las ciencias cognitivas: tendencias y perspectivas. Cartografia de las ideas actuales. Barcelona: Gedisa, 1990, 120 p.

VÉDrine, Hélène (1990). Les grandes conceptions de l'imaginaire de Platon à Sarte et Lacan. París: Livre de Poche, 1990,160 p.

WATZLAWCK, Paul (1976). ¿Es real la realidad? Confusion, desinformación, comunicacion. Barcelona: Herder, 5.a ed. 1992, 272 p.

WatzlaWick, Paul (comp.). (1981). La realidad inventada. ¿Como sabemos lo que creemos saber? Barcelona: Gedisa, 1989, 278 p.

WATZlaWICK, Paul 8 KRIEG, Peter (Hrsg.). (1991). Das Auge des Betrachters. Beiträge zum Konstruktivismus. Festschrift fïr H.von Foester. Munich: Piper, 1991, $278 \mathrm{p}$.

WaRNoCK, Mary (1976). La imaginacion. México: FCE, 1981, 365 p.

WeBER, Max (1922). Wirtschaft und Gesellschaft. Tübingen: J.C.B. Mohr (Paul Siebeck). $1985,945 \mathrm{p}$.

WeimanN, R. \& Gumbrecht, H.U. (Hrgb.). (1991). Postmoderne-globale Differenz. Frankfurr: Suhtkamp, 1991, 385 p. 